\title{
OSA Prevalence in a General Pediatric Craniofacial Population
}

\author{
Ian Canepa, BS; Tarek Elshebiny, BDS., MSD, Manish Valiathan; BDS., MDS., DDS., MSD
}

Case Western Reserve University, School of Dental Medicine, Department of Orthodontics, Craniofacial Clinic

\begin{abstract}
Study Objectives: Obstructive sleep apnea (OSA) is a common disorder characterized by collapse of the upper airway during sleep and requires a multidisciplinary management approach. There has yet to be a study that is able to compare a craniofacial (CF) population sample to a sample of the general public that is from a similar clinic setting. The aim of this study was to determine the prevalence of positive OSA screenings in a CF population sample treated in the CF clinic of a dental school, and compare it to a previously collected sample from the orthodontic clinic of the same dental school. ${ }^{1}$

Methods: At a tertiary care CF orthodontic clinic in a dental school, children between the ages of 7 to 18 years were screened for OSA using the validated pediatric sleep questionnaire (PSQ) screening tool. An identical study was previously conducted in the orthodontic clinic of the same dental school. ${ }^{1}$

Results: Scores from the PSQ were calculated and $21 \%$ of our sampled CF population was considered to be at high risk. However, the PSQ scores of the patients seeking orthodontic treatment in the core clinic were previously calculated and only $7 \%$ were considered to be at high risk of OSA. ${ }^{1}$

Conclusions: Compared to the general pediatric population, patients with $\mathrm{CF}$ anomalies are three times more likely to be considered at high risk for OSA. CF orthodontists must administer PSQs as part of their medical record taking, and be well trained in both dental and nondental management of patients with potential OSA. ${ }^{1}$
\end{abstract}

Keywords: craniofacial; general; obstructive sleep apnea; pediatric

Citation: Canepa I, Elshebiny T, Valiathan M. OSA Prevalence in a General Pediatric Craniofacial Population. J Dent Sleep Med. 2019;6(3)

\section{INTRODUCTION}

Obstructive sleep apnea (OSA) is a common disorder characterized by repetitive collapse of the upper airway during sleep, resulting in nocturnal hypoxemia and recurrent arousals. $^{2}$ This can lead to oxyhemoglobin desaturations, which has been linked to high blood pressure, heart attacks, strokes, car accidents, work-related accidents, and depression. ${ }^{3}$ The prevalence of OSA in adult men and women has been estimated by prospective studies with the use of polysomnography (PSG) to be $13 \%$ and $6 \%$ respectively; in the general pediatric population it is estimated to be between $1.2 \%$ to $5.8 \%$. $^{4-6}$

Craniofacial (CF) deformities have been reported by surveillance studies to occur in approximately 1 in every 500 live births. $^{7}$ Because of the various skeletofacial morphologies exhibited in patients with CF deformities, such as midfacial hypoplasia, micrognathia, and soft-tissue variations such as macroglossia, they are at a higher risk of acquiring OSA early in life and even following corrective surgery. ${ }^{8}$ Although there are difficulties in the screening process for patients with $\mathrm{CF}$ deformities, a major CF center used the Pediatric Sleep Questionnaire (PSQ) and measured an incidence of $28 \%$ in more than 200 of their patients. ${ }^{9}$ Although PSG is the gold standard for diagnosing OSA, issues with cost, time, and access for patients have hampered its general use in research. Thus, the PSQ has been used as a surrogate by many researchers. It is a parent-completed, validated screening tool that predicts moderate to severe OSA with a sensitivity of $83 \%$ and specificity of $87 \%$ in healthy children. ${ }^{10,11}$

A higher rate of positive OSA screenings in both the syndromic (32\%) and nonsyndromic (14\%) patient populations with cleft lip and palate $(\mathrm{CL} / \mathrm{P})$ populations has been shown by past research through the use of the PSQ. ${ }^{12}$ As such, clefts are the most common form of CF anomaly, and can be used to obtain a more homogenous sample to investigate. ${ }^{12,13}$ There has yet to be a study that compares a $\mathrm{CF}$ population sample to a control sample that is from the same clinical setting. Therefore, the aim of this study was to determine the prevalence of positive OSA screenings among the population with $\mathrm{CF}$ anomalies treated in the dental school's specialized CF clinic, and compare it to the previously collected prevalence among the general pediatric population treated in the core orthodontic clinic of the same dental school. ${ }^{14}$ This was accomplished through the coordination between the graduate orthodontic clinic and the specialized CF clinic within the same school. Also, although past studies have focused on specific CF disorders such as facial clefts, this sample is a more heterogeneous $\mathrm{CF}$ population meant to investigate if a more generalized link exists. The PSQ, a validated screening tool, was used to measure the percentage of pediatric patients at high risk in the $\mathrm{CF}$ clinic and compare it to the percentage in the graduate orthodontic clinic, which was documented in a separate study. 


\section{METHODS}

An Institutional Review Board-approved, retrospective questionnaire review was performed on consecutive patients between the ages of 7 and 18 years treated at the CF clinic of the orthodontic department at Case Western Reserve University School of Dental Medicine in Cleveland, Ohio between May 2017 and July 2017. Following routine clinical protocols in the standard of clinical care, a paper copy of the PSQ (Figure 1) was administered to all guardians during appointments either before or early in the patients' orthodontic treatment. The PSQ contains a list of 22 "yes/no" questions that address the presence of symptoms related to abnormal breathing, daytime sleepiness, and behavioral issues. An additional 6 questions addressing factors that influence the patient's upper airway volume were added to the questionnaire, for a total of 28 possible questions. A questionnaire is considered to have a positive predication of moderate to severe OSA when its ratio of positively answered questions is $\geq .33$. Questions that were left blank were removed from the survey so as to only measure answered questions. At times the guardians filling out the questionnaires would answer "sometimes", which was considered a positive response, whereas a response of "I don't know" was deemed negative. Patients indicated their birth date, ethnicity, and any underlying syndromes as part of the questionnaire; body mass index was not regularly recorded at the time of the study.

\section{RESULTS}

The guardians of a total of 98 patients filled out the PSQ during the study period. A total of $21 \%$ of the screenings were determined to be positive, indicating these patients are at high risk of experiencing OSA. An illustration of the PSQ score distribution is given in Figure 2. The mean age at the time of the PSQ completion was $12.96 \pm 3.17$ years. The study population was predominantly Caucasian with an even distribution between male and female patients; this information is outlined in Table 1. Forty-two percent of the population had either a unilateral or bilateral cleft lip or palate, and of these patients $14 \%$ had a positive OSA screening. Similarly, attention deficit hyperactivity disorder (ADHD) was diagnosed or previously diagnosed in $14 \%$. The relative risk and an odds ratio were calculated using IBM SPSS version 25 (IBM, Armonk, NY). The relative risk of the population with a CF anomaly compared to the result of the study done on the general population in the core orthodontic clinic was $2.95[1.69,5.13](\mathrm{P}=0.0001)$ and the result of the odds ratio was $3.48[1.82,6.67](\mathrm{P}=0.0002)$. A further breakdown of population descriptors is shown in Tables 1 and 2. These descriptors have been placed alongside the prevalence of positive OSA screening in
Table 1. Distribution of Age, Sex and Ethnicities in CF Population

\begin{tabular}{llll}
\hline & & Frequency & $\begin{array}{l}\text { Frequency } \\
\text { positive test }\end{array}$ \\
\hline Age $(\mathrm{y})$ & $12.96 \pm 3.17$ & & \\
\hline Sex $(\mathrm{n})$ & Female & 51 & 7 \\
\hline & Male & 47 & 14 \\
\hline $\begin{array}{l}\text { Ethnicity } \\
(\mathrm{n})\end{array}$ & Asian & 8 & 1 \\
\hline & Black & 17 & 4 \\
\hline & Hispanic & 8 & 2 \\
\hline & White & 55 & 12 \\
\hline & Other & 6 & 1 \\
\hline Total & Not-Reported & 4 & 1 \\
\hline \hline
\end{tabular}

Table 2. Distribution of Most Anomalies in CF Population

\begin{tabular}{|c|c|c|}
\hline CF Anomaly & $\begin{array}{c}\text { Frequency in } \\
\text { patient } \\
\text { population }\end{array}$ & $\begin{array}{l}\text { Frequency of } \\
\text { positive PSQ }\end{array}$ \\
\hline Cleft Palate & 6 & 1 \\
\hline Cleft L/P & 35 & 5 \\
\hline De Lange Syndrome & 1 & 0 \\
\hline Down's Syndrome & 4 & 2 \\
\hline Gorlin Syndrome & 1 & 0 \\
\hline Fetal Alcohol Syndrome & 2 & 1 \\
\hline Pierre-Robin Sequence & 3 & 1 \\
\hline Treacher-Collins Syndrome & 2 & 1 \\
\hline Sotos Syndrome & 2 & 1 \\
\hline Turners Syndrome & 2 & 2 \\
\hline Cleidocranial Dysplasia & 2 & 0 \\
\hline Ectodermal Dysplasia & 2 & 1 \\
\hline $\begin{array}{l}\text { Beckwith-Weidmann } \\
\text { Syndrome }\end{array}$ & 1 & 0 \\
\hline Craniofacial Microsomia & 2 & 0 \\
\hline Langer-Giedioin Syndrome & 1 & 0 \\
\hline Freeman-Sheldon & 1 & 0 \\
\hline Cherubism & 1 & 0 \\
\hline Pfeifer Syndrome & 1 & 0 \\
\hline Cri du Chat Syndrome & 1 & 0 \\
\hline Unspecific Craniosynostosis & 1 & 0 \\
\hline Special Needs & 30 & 6 \\
\hline Total & 98 & 21 \\
\hline
\end{tabular}


Figure 1. Distribution of patient PSQ scores. Red and Blue indicating the threshold of $33 \%$ which any equal or greater score (red) determines a positive screening indicating the patient is at "high risk" of suffering from moderate-severe OSA.

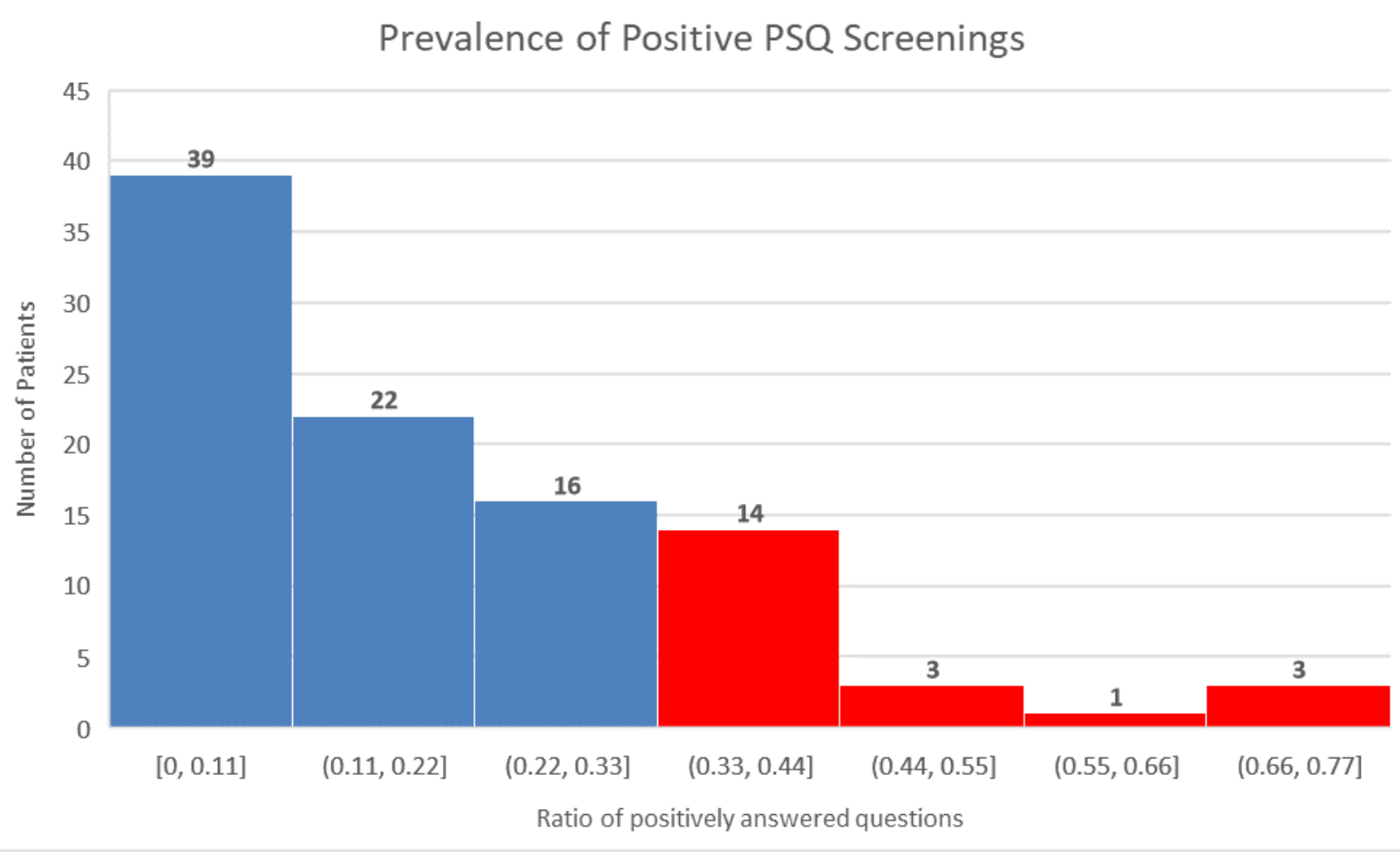

Table 3. CFA - Population with Craniofacial Anomalies. High Risk is determined by a ratio of .33 or greater positively answered questions on the PSQ.

\begin{tabular}{|c|c|c|c|c|c|}
\hline \multicolumn{6}{|c|}{ Population * Risk Cross Tabulation } \\
\hline & & & \multicolumn{2}{|c|}{ Risk } & \multirow[b]{2}{*}{ Total } \\
\hline & & & High & Low & \\
\hline \multirow[t]{4}{*}{ Population } & CFA & Count & 21 & 77 & 98 \\
\hline & & $\%$ within Population & $21.4 \%$ & $78.6 \%$ & $100.0 \%$ \\
\hline & Non-CFA & Count & 22 & 281 & 303 \\
\hline & & $\%$ within Population & $7.3 \%$ & $92.7 \%$ & $100.0 \%$ \\
\hline \multirow[t]{2}{*}{ Total } & & Count & 43 & 358 & 401 \\
\hline & & $\%$ within Population & $10.7 \%$ & $89.3 \%$ & $100.0 \%$ \\
\hline
\end{tabular}

\begin{tabular}{|c|c|c|c|}
\hline \multicolumn{4}{|c|}{ Risk Estimate } \\
\hline & \multirow[b]{2}{*}{ Value } & \multicolumn{2}{|c|}{ 95\% Confidence Interval } \\
\hline & & Lower & Upper \\
\hline $\begin{array}{l}\text { Odds Ratio for Population } \\
\text { (CFA / Non-CFA) }\end{array}$ & 3.483 & 1.820 & 6.666 \\
\hline For cohort Risk = High & 2.951 & 1.698 & 5.130 \\
\hline For cohort Risk $=$ Low & .847 & .760 & .944 \\
\hline $\mathrm{N}$ of Valid Cases & 401 & & \\
\hline
\end{tabular}


Figure 2. Pediatric Sleep Questionnaire (PSQ) distributed to all patients

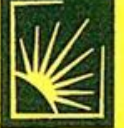

SCHOOL OF DENTAL MEDICINE

CASEWESTERNRESERVE

U N I VER S I T Y

Department of Orthodontics

Obstructive Sleep Apnea Screening

PATIENTS UNDER 18 YEARS OF AGE

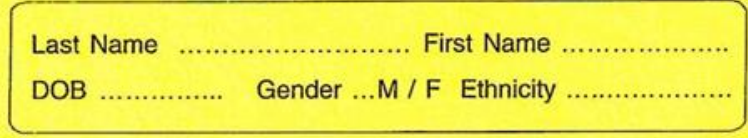

Date

Please answer on behalf of your child for the past month. If you don't know, circle "?"

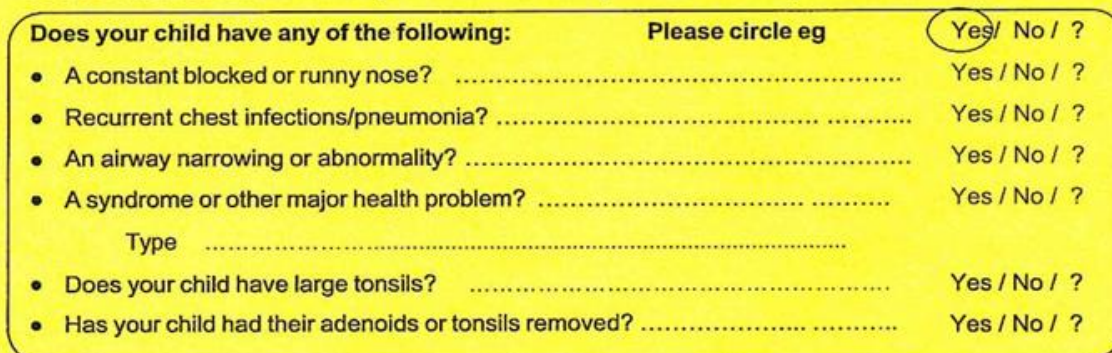

\footnotetext{
While sleeping, does your child...

1. snore more than half the time?

Yes/ No/?

2. always snore?

Yes/No/?

3. snore loudly?

4. have trouble breathing, or struggle to breathe?

$\mathrm{Yes} / \mathrm{No} /$ ?

Yes/ $\mathrm{No} /$ ?

$\mathrm{Yes} / \mathrm{No} /$ ?

5. have "heavy" or loud breathing?

Yes/No/?

6. have you ever seen your child stop breathing during the night?

Yes/ No/?

7. tend to breathe through the mouth during the day?

Yes/ No/?

8. have a dry mouth on waking up in the morning?

Yes/No/?

Yes/No/?

Yes/ $\mathrm{No} /$ ?

11. have a problem with sleepiness during the day?

Yes/No/?

12. has a teacher commented that your child appears sleepy during the day? ....

$\mathrm{Yes} / \mathrm{No} /$ ?

13. is it hard to wake your child up in the morning?

Yes/ $\mathrm{No} /$ ?

14. does your child wake up with headaches in the morning?

Yes/ No/?

15. did your child stop growing at a normal rate at any time since birth?

$\mathrm{Yes} / \mathrm{No} /$ ?

My child often ...

17. does not seem to listen when spoken to directly.

Yes/No/?

18. has difficulty organizing task and activities.

19. is easily distracted by extraneous stimuli.

20. fidgets with hands or feet or squirms in seat.

21. is 'on the go' or often acts as if 'driven by a motor'.

Yes/ $\mathrm{No} /$ ?

Yes/ $\mathrm{No} /$ ?

$\mathrm{Yes} / \mathrm{No} /$ ?

$\mathrm{Yes} / \mathrm{No} /$ ?

22. interrupts or intrudes on others (e.g. butts into conversations or games). .......

$\mathrm{Yes} / \mathrm{No} /$ ?
} 
Table 2 . The tables generated in data analyses can be found on Table 3.

\section{DISCUSSION}

Prospective administration, as well as retrospective review, of the PSQ sleep apnea screening tool was used in the specialized CF clinic to report the prevalence of positive OSA screenings in a population of patients with $\mathrm{CF}$ anomalies. The prevalence of children with a positive screening was $21 \%$. Recently a similar study, titled Sleep disordered breathing in children seeking orthodontic care and is cited below, was performed in the core orthodontic clinic of the same dental school, which measured a $7 \%$ prevalence of positive PSQ screenings in the general pediatric population using a sample of 303 patients. ${ }^{14}$ Relative to the general pediatric population in the region, patients with $\mathrm{CF}$ anomalies were more than three times more likely to screen positive for moderate to severe OSA. Of 41 patients who exhibited cleft lip and palate, 6 were positive screenings, meaning that $14 \%$ of the population with clefts were determined to be at high risk for OSA. This is consistent with past studies focusing on the specific patient population. ${ }^{12,15}$

Past studies have been limited by the lack of a true pediatric population sample from the same site for comparison. ${ }^{11}$ Some have used samples from other specialized clinics such as a sleep clinic, but this study is unique in that the measured $\mathrm{CF}$ population sample as well as the general pediatric population sample are from the same area; the only difference is the physical clinic, in the same building, in which care was provided. ${ }^{14}$ This eliminates variability that would have been present had the populations been from different geographic locations, and in turn, strengthens the study by providing more generalizable results.

The results from this study not only agree with past studies in terms of specific population measurements, but build upon them and show a more generalized trend that any patient with a $\mathrm{CF}$ anomaly is at a higher risk of experiencing OSA than those without a CF anomaly. Compared to the study conducted on the general pediatric population of the dental school, the prevalence of positive screenings was three times higher among the population with a CF anomaly; the odds ratio and relative risk support that this population is at greater odds and more likely experience OSA. Although more in-depth statistics and objective study designs will need to be done to continue investigating this subject, the descriptive statistics should show practitioners that this correlation exists.

Undiagnosed pediatric OSA has been linked to various developmental defects spanning neurobehavioral, cardiovascular, and endocrine systems. ${ }^{16}$ A total of $14 \%$ of the patients who screened positive indicated that they have received a previous diagnosis of ADHD. Because pediatric OSA has been associated with delays in neurodevelopment it raises the recent concerns that $\mathrm{ADHD}$ or other attention/social disorders may be associated/secondary symptoms to prolonged undiagnosed pediatric OSA. ${ }^{17,18}$ This is an important subject for further research that may reveal more on the multifaceted and multisystem effect OSA can have, especially in the pediatric population. It also indicates how early and accurate diagnosis is vital in the treatment of children with CF anomalies. Because orthodontists tend to see children with $\mathrm{CF}$ anomalies frequently and over long spans of time, it is critical that the curriculum of accredited orthodontic programs document that residents demonstrate competence in the treatment of patients at a higher risk for OSA.

An obvious limitation of this study is the inability of PSQ to provide an objective diagnosis of OSA. The gold standard of OSA diagnosis is PSG, which was not used and comes with considerations of its own such as costs, time commitment, and patient access to a proper sleep clinic. However, the PSQ has been validated with a sensitivity and specificity of 0.83 and 0.87 , respectively, for diagnosis of moderate to severe OSA in the general population. It was validated through the use of PSG to truly determine the presence of OSA. ${ }^{19}$ Another limitation of the PSQ is that although its use has been validated to correctly predict patients with OSA in the general population, it has yet to be specifically validated for a pediatric population with $\mathrm{CF}$ anomalies. OSA may have different etiologies in this population due to a difference in their upper airway and $\mathrm{CF}$ morphologies. ${ }^{20}$ In spite of this limitation, until more sophisticated and practical tools are available to diagnose OSA, the PSQ and screening questionnaires are viable options to screen this vulnerable population of patients. Portable PSG could be used in a future study as a means to measure more objective results while mitigating some of the inconveniences associated with traditional PSG testing.

\section{CONCLUSION}

When compared to the study that was conducted in the dental school orthodontic clinic by statistical analysis, it is clear that patients with $\mathrm{CF}$ anomalies are more than three times more likely to be at high risk of experiencing OSA than patients without CF anomalies. Thus, it is critical that $\mathrm{CF}$ orthodontists routinely administer PSQs as part of their medical record taking, and are well trained in both dental and nondental management of patients with potential OSA.

\section{REFERENCES}

1. ACPA's 75th Annual Meeting Abstracts. Cleft Palate Craniofac J. 2018; 55(1_suppl):1-123.

2. Malhotra A, White DP. Obstructive sleep apnea. Lancet. 2002;360:237-245.

3. Franklin KA, Lindberg E. Obstructive sleep apnea is a common disorder in the population-a review on the epidemiology of sleep apnea. J Thorac Dis. 2015;7:1311-1322. 

Increased prevalence of sleep-disordered breathing in adults. Am J Epidemiol. 2013;177(9):1006-1014.

5. Li AM, So HK, Au CT, et al. Epidemiology of obstructive sleep apnea in Chinese children: a two-phase community study. Thorax. 2010;65(11):991-997

Bixler EO, Vgontzas AN, Lin HM, et al. Sleep disordered breathing in children in a general population sample: Prevalence and risk factors. Sleep. 2009;32(6):731-736.

7. Byvaltsev V, Belykh O, Belykh E. New aspects in the epidemiology of craniofacial anomalies. World Neurosurg. 2012;77(5-6):599-600.

8. Marino A, Malagnino I, Ranieri R, Villa MP, Malagola C. Craniofacial morphology in preschool children with obstructive sleep apnoea syndrome. Eur J Paediatr Dent. 2009;10(4):181-184.

9. Bozzini MFR, Di Francesco RC. Managing obstructive sleep apnoea in children: the role of craniofacial morphology. Clinics. 2016;71(11):664-666.

10. Paliga JT, Tahiri Y, Silvestre J, Taylor JA. Screening for obstructive sleep apnea in children treated at a major craniofacial center. $J$ Craniofac Surg. 2014;25(5):1762-1765.

11. Chervin RD, Hedger K, Dillon JE, Pituch KJ. Pediatric sleep questionnaire (PSQ): Validity and reliability of scales for sleep disordered breathing, snoring, sleepiness, and behavioral problems. Sleep Med. 2000;1(1):21-32.

Silvestre J, Tahiri Y, Paliga JT, Taylor JA. Incidence of positive screening for obstructive sleep apnea in patients with isolated cleft lip and/or palate. Plast Surg (Oakv). 2014;22(4):259-263.

13. Silvestre J, Tahiri Y, Paliga JT, Taylor JA. Screening for obstructive sleep apnea in children with syndromic cleft lip and/or palate. J Plast Reconstr Aesthet Surg. 2014;67(11):1475-1480.

14. Rohra AK Jr, Demko CA, Hans MG, Rosen C, Palomo JM. Sleep disordered breathing in children seeking orthodontic care. Am J Orthod Dentofac Orthop. 2018;154(1):65-71.

15. Capdevila OS, Kheirandish-Gozal L, Dayyat E, Gozal D. Pediatric obstructive sleep apnea: complications, management, and long-term outcomes. Proc Am Thorac Soc. 2008;5(2):274-282.

16. Sedky K, Bennett DS, Carvalho KS. Attention deficit hyperactivity disorder and sleep disordered breathing in pediatric populations: a meta-analysis. Sleep Med Rev. 2014;18(4):349-356.

17. Gozal D, Kheinrandish-Gozal L. Neurocognitive and behavioral morbidity in children with sleep disorders. Curr Opin Pulm Med. 2007;13(6):505-509.

18. Lewis CW, Jacob LS, Lehmann CU; Section on Oral Health. The primary care pediatrician and the care of children with cleft lip and/or cleft palate. Pediatrics. 2017 May;139(5).

19. Perkins JA, Sie K, Milczuk H, Richardson MA. Airway management in children with craniofacial anomalies. Cleft Palate Craniofac J. 1997;34(2):135-140.

20. Tan HL, Kheirandish-Gozal L, Abel F, Gozal D. Craniofacial syndromes and sleep-related breathing disorders. Sleep Med Rev. 2016;27:74-88

\section{SUBMISSION \& CORRESPONDENCE INFORMATION}

\section{Submitted for publication January 18, 2019 \\ Submitted in final revised form March 11, 2019 \\ Accepted for publication April 26, 2019}

Address correspondence to Ian Canepa, BS, 9601

Chester Avenue, Cleveland, $\mathrm{OH}$ 44106; Email: Icc10@case.edu

\section{DISCLOSURE STATEMENT}

The authors have no conflicts of interest to disclose. 